\title{
Mechanical and Morphological Analysis of Aluminum Composite Material
}

\author{
P.V.Narasimha Rao, Periyasamy, Vasudevarao, R.Sharavanan.S, Ramanan.N
}

\begin{abstract}
Now a days industry focused on a light weight concept of the material. The light weight material also used in a engineering projects. In the light weight material as more useful in a engineering application. So in the work focused on the light weight materials. In this work Al 6061 B4C and Sic composite material. The material compared to the normal material is light weight. also the in this work focused on the wear behavior of the material. In this work mainly focused on the mechanical and Metallurgical properties of sic composites. The objective of the paper is reduce wear and give light weight material. In this paper mechanical and light weight Property discussed. The mechanical and SEM surface also discussed. in this paper compared the different composition and finally got a result of the better composition.
\end{abstract}

Keywords: light weight material, wear behavior, material character station, fracture surface

\section{INTRODUCTION}

In the paper discussed with mechanical and metallurgical properties of composites $^{[1,2]}$. In this paper discussed with the al sic composite material and great wear resistance properties $^{[4,5]}$. In this paper discussed with the excellent wear and corrosion properties. ${ }^{[6]}$ AMMC studied the classic material itself. The mechanical and metallurgical properties of al-sic composites ${ }^{[7]}$ in this paper discussed with the al MMC. And greater advantage of the corrosion and wear properties $^{[8]}$, in this paper discussed with the $\mathrm{Al} 7075$ material with higher wear and corrosion properties ${ }^{[9]}$. The $\mathrm{Al} 6061$ sic properties discussed with flexural and impact strength of the properties $^{[10]}$

\section{COMPOSITION OF ALUMINUM METAL MATRIX COMPOSITES}

\begin{tabular}{|c|c|c|c|}
\hline Samples & AA6061 (\%) & SiC(\%) & B $_{4} \mathrm{C}(\%)$ \\
\hline
\end{tabular}

Manuscript published on November 30, 2019.

* Correspondence Author

P.V. Narasimha Rao *, Research Scholar, Department of Mechanical Engineering, St Peter's Institute of Higher Education and Research, Avadi Chennai

Periyasamy, Prof, Department of Mechanical Engineering, St Peter's Institute of Higher Education and Research, Avadi Chennai

Vasudeva Rao, Research Scholar, Department of Mechanical Engineering, St Peter's Institute of Higher Education and Research, Avadi Chennai

Sharavanan, Associate Prof, Department of Mechanical Engineering, Vistas, Pallavaram, Chennai

Ramanan Sr Engineer, Synce Engineering Service, chennai

(C) The Authors. Published by Blue Eyes Intelligence Engineering and Sciences Publication (BEIESP). This is an open access article under the CC-BY-NC-ND license http://creativecommons.org/licenses/by-nc-nd/4.0/

\begin{tabular}{|c|c|c|c|}
\hline 1 & 98 & 1 & 1 \\
\hline 2 & 96 & 2 & 2 \\
\hline 3 & 94 & 3 & 3 \\
\hline 4 & 92 & 4 & 4 \\
\hline
\end{tabular}

\section{MATERIAL SELECTION}

In this work the material has been used $\mathrm{Al} 6061$ and Sic material as various percentages. The percentage of the material discuss as the table. The MMC used for casting purpose stir casting setup has been used. The wetting agent Magnesium has been used.

\section{COMPOSITION OF COMPOSITES FABRICATED}

\begin{tabular}{|c|c|c|c|}
\hline Samples & $\begin{array}{c}\text { AA6061 } \\
\mathbf{( \% )}\end{array}$ & $\mathbf{S i C}(\mathbf{\%})$ & $\mathbf{B}_{\mathbf{4}} \mathbf{C}(\mathbf{\%})$ \\
\hline 1 & 98 & 1 & 1 \\
\hline 2 & 96 & 2 & 2 \\
\hline 3 & 94 & 3 & 3 \\
\hline 4 & 92 & 4 & 4 \\
\hline
\end{tabular}

\section{FABRICATION OF THE COMPOSITES - STIR CASTING PROCESS}

Stir casting method shown in a figure. The stir method bootom curing process has been used. Here matrix sic has been used. The process is stirrer has bottom surface has been process. The stir casting set up has been used for a better solidifying material.

\section{METHODOLOGY OF STIR CASTING}

In this method stir casting solid crucible furnace has been used. Primary the aluminum material has been pre heated. The material sic material has been also preheated. In this preheated the wettability removal method. For more wettability the porosity will be occur. Secondary the aluminum material has been melted. The aluminum material melted up to 780 degree. Finally the stirrer will be rotate up to $2000 \mathrm{rpm}$. That time the Sic were mixed in the solidifying. 


\section{Mechanical and Morphological Analysis of Aluminum Composite Material}

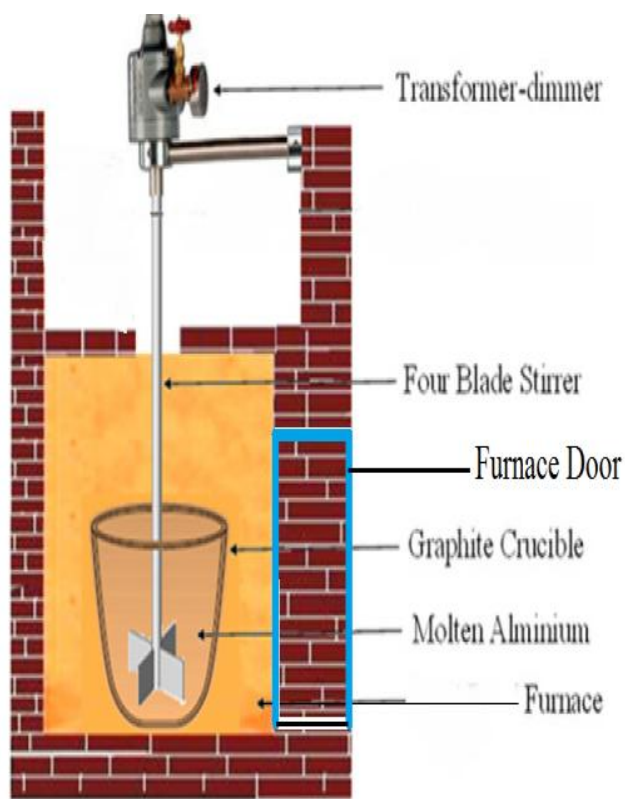

FIG 1. Fabrication of metal matrix composite using stir casting method

VII. MECHANICAL TESTING

Theoretical Vs Actual Densities of $\mathrm{Al}_{-} \mathrm{B}_{4} \mathrm{C}-\mathrm{SiC}$ Composites

- Theoretical Density $\quad$ Actual Density

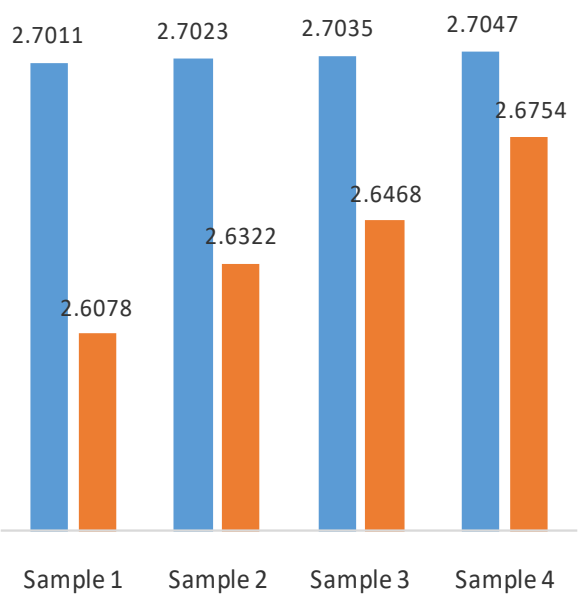

Fig 2. TheoreticalVs Actual Densities of $\mathrm{Al}-\mathrm{B}_{4} \mathrm{C}-\mathrm{SiC}$ Composites

The above image shown as the difference between theoreticalVs actual densities of composite material.

\section{TENSILE TEST}

The tensile test result discussed with table the tensile test generally taken from D8 standard. The Utm machine used for test on the samples

Result of Tensile Test

Table 1. Force Vs stroke for tensile test

\begin{tabular}{|l|c|c|c|c|}
\hline $\begin{array}{c}\text { Name of } \\
\text { Sample }\end{array}$ & $\begin{array}{c}\text { Break } \\
\text { load } \\
\mathbf{( k N )}\end{array}$ & $\begin{array}{c}\text { Maximum } \\
\text { displacement } \\
\mathbf{( m m )}\end{array}$ & $\begin{array}{c}\text { Tensile } \\
\text { strength } \\
\mathbf{( M P a )}\end{array}$ & $\begin{array}{c}\text { Elongation } \\
\mathbf{( \% )}\end{array}$ \\
\hline Sample 1 & 6.85 & 10.12 & 127.54 & 7.12 \\
\hline Sample 2 & 6.72 & 11.38 & 127.28 & 7.12 \\
\hline Sample 3 & 7.35 & 12.12 & 127.50 & 6.15 \\
\hline Sample 4 & 8.25 & 8.50 & 118.20 & 6.45 \\
\hline
\end{tabular}

\section{FLEXURAL TEST}

The Flextural test result discussed with table the tensile test generally taken from D8 standard. The Utm machine usedfor test on the samples

Table 2.Force Vs stroke for Flexural test

\begin{tabular}{|l|c|c|c|}
\hline $\begin{array}{c}\text { Name of } \\
\text { Sample }\end{array}$ & $\begin{array}{c}\text { Flexural } \\
\text { Break } \\
\text { Load (kN) }\end{array}$ & $\begin{array}{c}\text { Maximum } \\
\text { deflection } \\
\text { (mm) }\end{array}$ & $\begin{array}{c}\text { Flexural } \\
\text { strength (MPa) }\end{array}$ \\
\hline Sample 1 & 1.74 & 9.5 & 111.02 \\
\hline Sample 2 & 3.42 & 8.42 & 147.45 \\
\hline Sample 3 & 3.54 & 8.32 & 159.42 \\
\hline Sample 4 & 4.64 & 8.2 & 224.25 \\
\hline
\end{tabular}

\section{RESULT OF IMPACT TEST}

The impact test result discussed with table the impact test generally taken from D3 standard. The Utm machine used for test on the samples

Result of Impact Test

Table 3. Impact Test

\begin{tabular}{|c|c|}
\hline Name of Sample & Energy absorbed (J) \\
\hline Sample 1 & 8.11 \\
\hline Sample 2 & 8.15 \\
\hline Sample 3 & 7.2 \\
\hline Sample 4 & 8.45 \\
\hline
\end{tabular}

\section{RESULT OF HARDNESS TEST}

The Brinell hardness test was carried out, and the results are furnished in table 6.4. The hardness of sample 4 is higher than other samples due to the presence of high amount of silicon carbide and boron carbide. 


\section{RESULT OF HARDNESS TEST}

\section{Table 4. Hardness Value in BHN}

\begin{tabular}{|l|l|l|l|}
\hline $\begin{array}{c}\text { Name of } \\
\text { Sample }\end{array}$ & Trial 1 & Trial 2 & Trial 3 \\
\hline Sample 1 & 31.2 & 30.9 & 30.2 \\
\hline Sample 2 & 31.4 & 31.2 & 31.4 \\
\hline Sample 3 & 31 & 33 & 31 \\
\hline
\end{tabular}

\section{MICROSTRUCTURE ANALYSIS OF SAMPLES}

The images shown in a fracture surface of the Scanning Electron Microscope images. The images shown in a $250 \mathrm{X}$ magnification. The images has shown in a ductile fracture

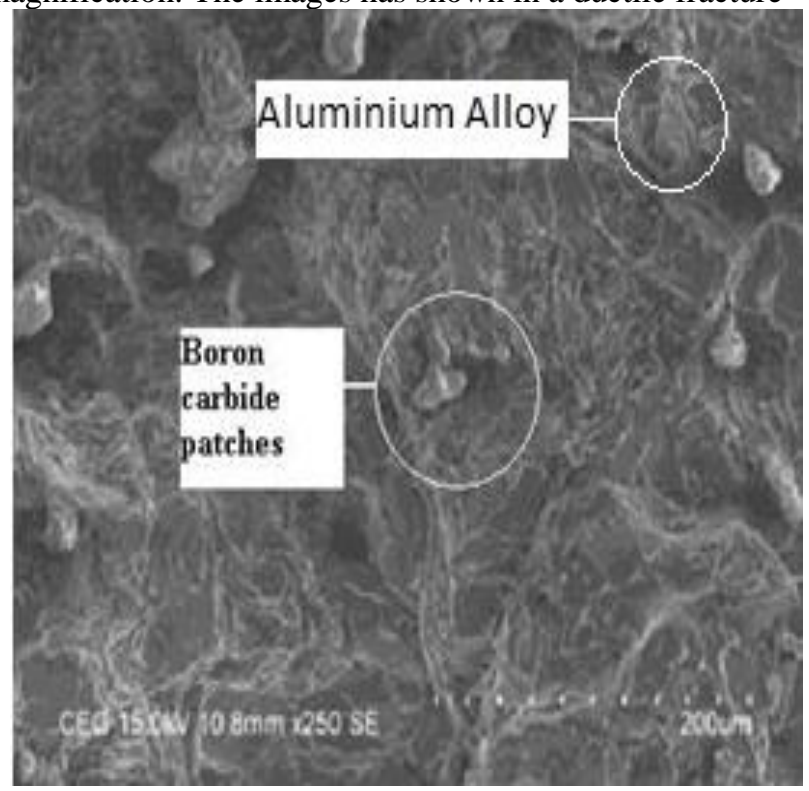

Fig 3. SEM image of tensile tested specimen

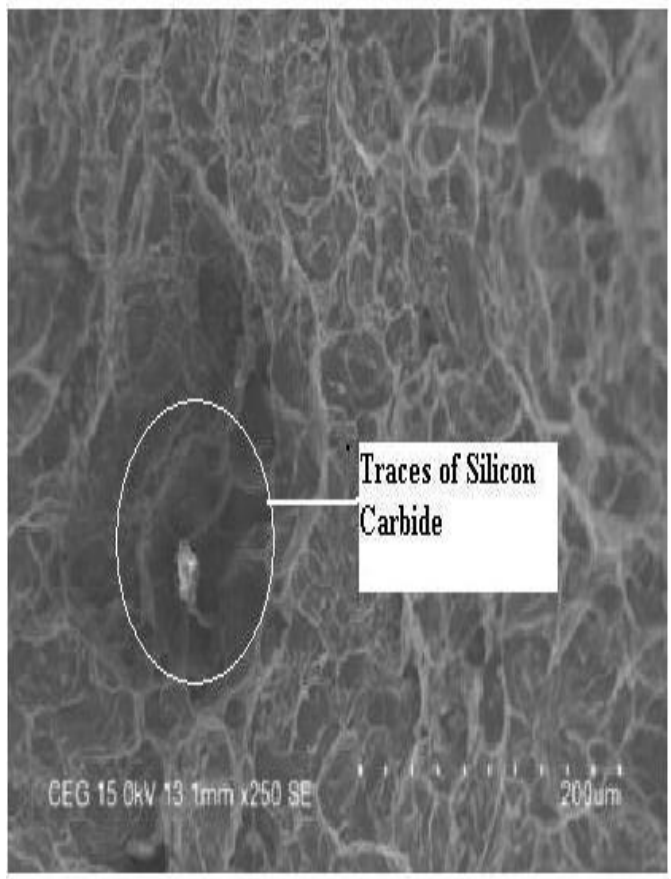

Fig 4. SEM image of flexural tested specimen
The SEM image shown in figures the figure shown in a cup and cone it will produced. So it will ductile fracture and the silicon carbide image shown in figure. The silicon carbon distributed evenly in the surface.

\section{RESULT AND DISCUSSION}

A. Tensile Test

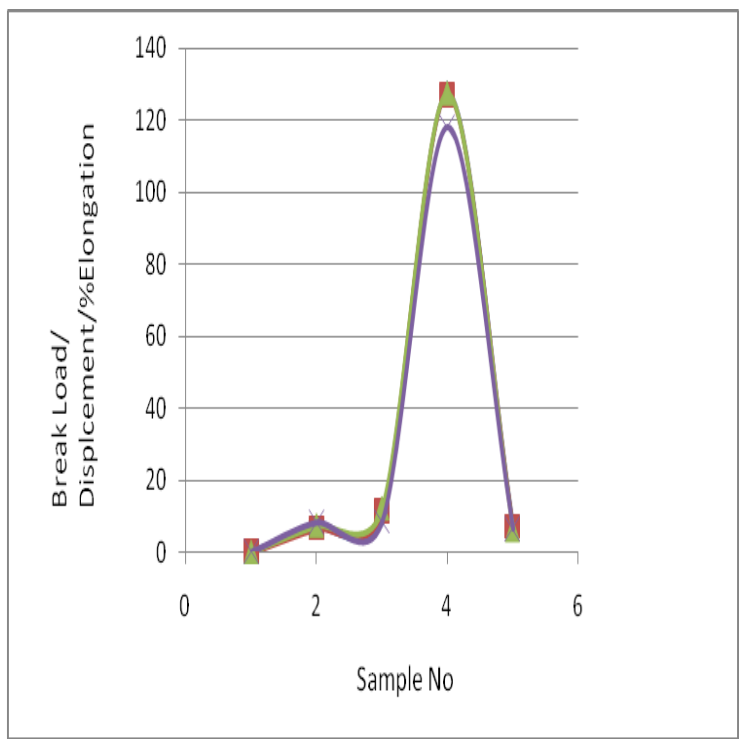

Fig 5. Tensile Test Result

The tensile test result shown in a graph. The values shown in a break load, displacement and \% of elongation. The maximum breaking load $127.54 \mathrm{mpa}$. It shown in a repeatability values closer to original values. So the ultimate value $127.54 \mathrm{MPa}$.

B. Flexural test

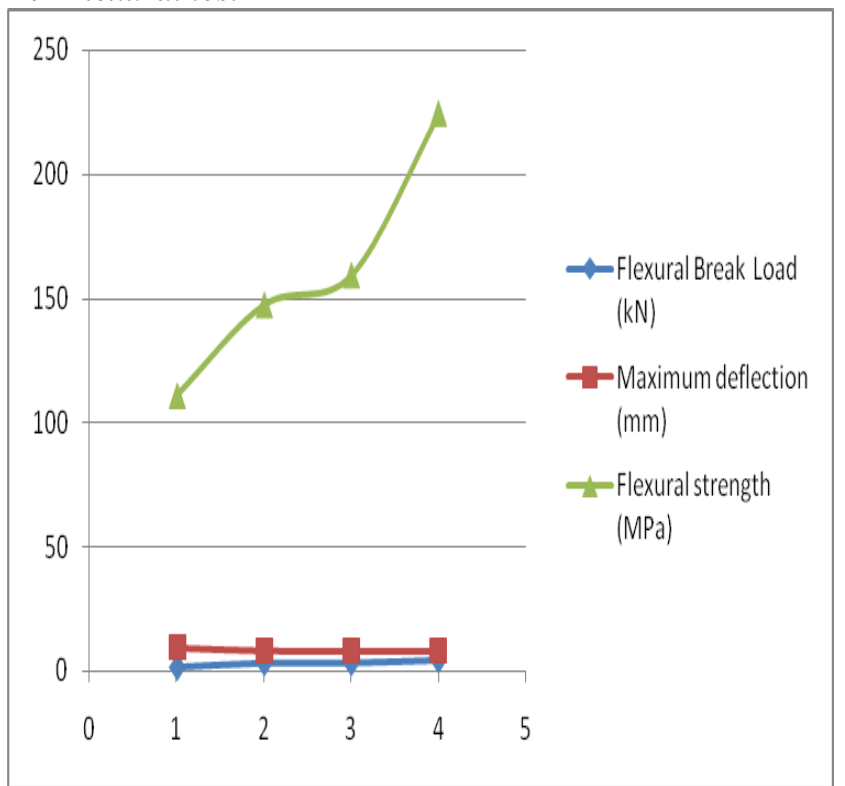

Fig 6. Flexural Test

Flexural test shown in fig. the maximum flexural load $230 \mathrm{kN}$. The maximum deflection $0.2 \mathrm{~mm}$. the values shown in a the more flexural and bending strength of the materials

C. Impact test 


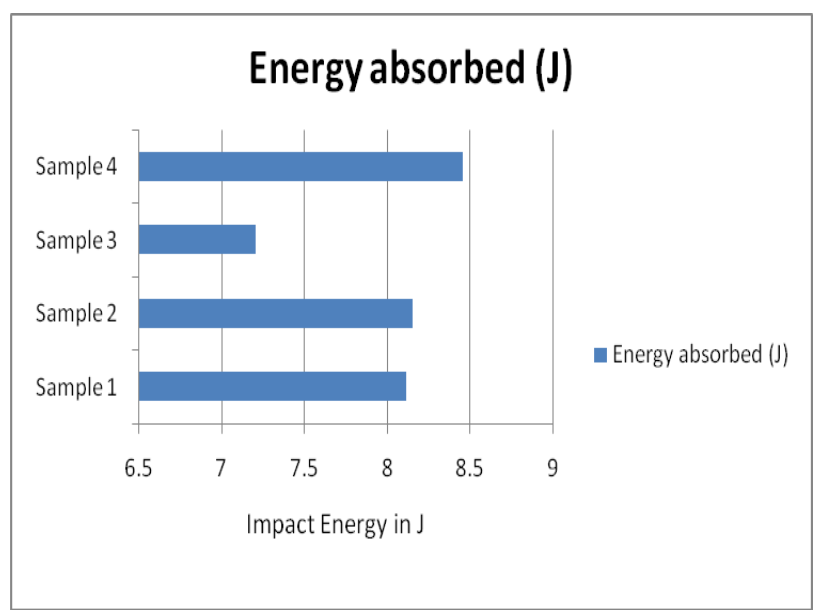

Fig 7. Imapct test.

The impact test shown in a graph. The maximum impact energy is $8.3 \mathrm{j}$. it is more impact energy absorbed. The result shown that more impact energy observed.

\section{CONCLUSION}

In this work discussed with al sic and b4c composite. The different sample discussed with the finally the $92 \%$ aluminum each $4 \%$ sic and b4c composite have given excellent results. The composite have high flexural strength hence it have used for bending properties materials. It has high impact load carry material. So it has used for a bumper material. In this work continuous with wear character station. The density analysis also done in the projects. So in the material light weight so excellent wear resistance are to achieved.

\section{REFERENCES}

1. G. O. Young, "Synthetic structure of industrial plastics (Book style with paper title and editor)," in Plastics, 2nd ed. vol. 3, J. Peters, Ed. New York: McGraw-Hill, 1964, pp. 15-64.

2. W.-K. Chen, Linear Networks and Systems (Book style). Belmont, CA: Wadsworth, 1993, pp. 123-135.

3. H. Poor, An Introduction to Signal Detection and Estimation. New York: Springer-Verlag, 1985, ch. 4.

4. B. Smith, "An approach to graphs of linear forms (Unpublished work style)," unpublished.

5. E. H. Miller, "A note on reflector arrays (Periodical style-Accepted for publication)," IEEE Trans. Antennas Propagat., to be published.

6. J. Wang, "Fundamentals of erbium-doped fiber amplifiers arrays (Periodical style-Submitted for publication)," IEEE J. Quantum Electron., submitted for publication.

7. C. J. Kaufman, Rocky Mountain Research Lab., Boulder, CO, private communication, May 1995.

8. Y. Yorozu, M. Hirano, K. Oka, and Y. Tagawa, "Electron spectroscopy studies on magneto-optical media and plastic substrate interfaces(Translation Journals style)," IEEE Transl. J. Magn.Jpn., vol. 2, Aug. 1987, pp. 740-741 [Dig. ${ }^{\text {th }}$ Annu. Conf. Magnetics Japan, 1982, p. 301].

9. M. Young, The Techincal Writers Handbook. Mill Valley, CA: University Science, 1989.

10. (Basic Book/Monograph Online Sources) J. K. Author. (year, month, day). Title (edition) [Type of medium]. Volume(issue). Available: http://www.(URL)

11. J. Jones. (1991, May 10). Networks (2nd ed.) [Online]. Available: http://www.atm.com

12. (Journal Online Sources style) K. Author. (year, month). Title. Journal [Type of medium]. Volume(issue), paging if given. Available: http://www.(URL) 